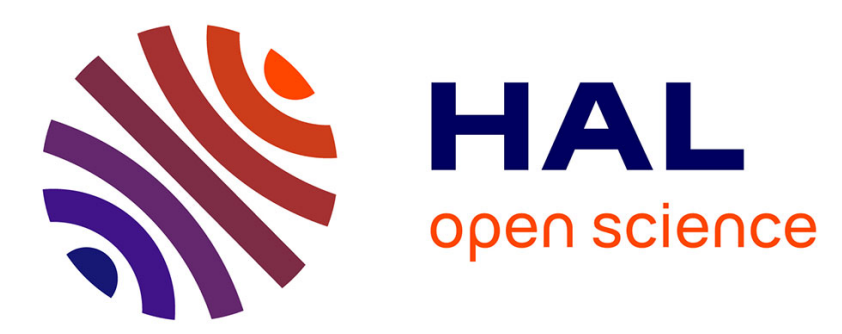

\title{
Framework Conditions for Forming Collaborative Networks on Smart Service Platforms
}

\author{
Volker Stich, Michael Kurz, Felix Optehostert
}

\section{To cite this version:}

Volker Stich, Michael Kurz, Felix Optehostert. Framework Conditions for Forming Collaborative Networks on Smart Service Platforms. 16th Working Conference on Virtual Enterprises (PROVE), Oct 2015, Albi, France. pp.193-200, 10.1007/978-3-319-24141-8_17 . hal-01437886

\section{HAL Id: hal-01437886 https://hal.inria.fr/hal-01437886}

Submitted on 17 Jan 2017

HAL is a multi-disciplinary open access archive for the deposit and dissemination of scientific research documents, whether they are published or not. The documents may come from teaching and research institutions in France or abroad, or from public or private research centers.
L'archive ouverte pluridisciplinaire HAL, est destinée au dépôt et à la diffusion de documents scientifiques de niveau recherche, publiés ou non, émanant des établissements d'enseignement et de recherche français ou étrangers, des laboratoires publics ou privés.

\section{(c)(1)}

Distributed under a Creative Commons Attribution| 4.0 International License 


\title{
Framework Conditions for Forming Collaborative Networks on Smart Service Platforms
}

\author{
Volker Stich $^{1}$, Michael Kurz ${ }^{1}$ and Felix Optehostert ${ }^{1}$ \\ ${ }^{1}$ Institute for Industrial Management at RWTH Aachen University, Campus-Boulevard 55, \\ 52074 Aachen, Germany \\ \{Volker.Stich, Michael.Kurz, Felix.Optehostert\}@fir.rwth-aachen.de
}

\begin{abstract}
Smart Products are ubiquitous in enterprise's businesses. They communicate over cross-company networks and generate a large quantity of data. By analyzing and filtering these data, enterprises are enabled to create innovative business models. These service innovations are offered to companies on service platforms. Furthermore, these platforms can be integrated in the innovation process. Users are enabled to voice their needs with respect to a particular service on this platform. A group of service enterprises address these demands by using the platform as a collaborative network and form a shortterm virtual enterprise. They jointly develop a customer-specific service. There are some obstacles that need to be overcome in order to operate such platforms and form collaborative networks on them. This paper identifies and analyses the platform's framework conditions which are required to address this issue and allow the enterprises to form a short-term virtual enterprise. Based on this work, the concept of such a platform can be defined in a next step.
\end{abstract}

Keywords: Service Innovation, Collaborative Network, Service Platform, Smart Service

\section{Introduction}

The use of information- and communication technologies in business and society are nowadays taken for granted [1]. Especially concerning the consumer service industry, the disruptive force of digitalization has changed business fundamentally. New digital platforms have changed the business structure for example in the music industry as well as the cinema and television industry. Old value added structures have been abolished and replaced by new innovative business models. Dominant players, ruling the market in this field by establishing platforms are e.g. Apple (iTunes), amazon and Netflix [2;3]. In comparison to consumer services, industrial services are executed in a business to business relationship. They are characterized by a high connection to the industrial good [3;4]. However, the obstacles for the digitalization of the business models of indusial services are much higher than in the consumer services. Three reasons for this can be identified. On the one hand the complexity of products and services is much higher in the business to business relationship. Industrial services have much higher requirements with regards to the qualifications of a service 
provider. Furthermore the markets for industrial services are much smaller and regional focused. Developing costs and market-introduction costs for new digital solutions do not seem to amortize. Finally entering the industrial service market is often very difficult. Consumer services can be offered and executed via internet whereas the connection of small and regionally focused service providers is more difficult.

However, these obstacles should not be seen as a general hindrance for the digitalization of the industrial service industry. These obstacles rather explain why the digitalization is growing fast in some markets whereas other markets are still lagging behind. However, in the industrial sector fundamentally changing forces already appear [5;6]. Established value creating chains will be changed fundamentally or will completely vanish. They will be substituted by value creating networks and virtual enterprises formed on platforms [7]. These value creating networks will not only change the process of executing services, but also the organizational structures and most importantly the way services are being engineered. The division of labor between producer, supplier and service provider as well as their business models will be changed by digitalization $[7 ; 6]$.

The place where producer, industrial service provider and software companies cooperate and form networks are upcoming digital ecosystems. Every company changing their way of thinking on value creation and using these ecosystems for their business models will have a competitive advantage [7]. Therefore the ongoing transformation of business models by digitalization will not only be a challenge but simultaneously a chance for small to medium sized businesses [7].

Now small to medium sized businesses have the chance to participate in building value creating networks. This can be achieved for e.g. by establishing new digital standards and enabling the access to data and information. One of the new digital standards can be platforms on which innovative services are engineered by a network of companies forming a short-term virtual enterprise. This platform can either be operated by one company or otherwise by a consortium of firms, in order to avoid a dominant party. These kinds of platforms can be an important part of the new digital value creating in networks. In the following paper the framework requirements for such a platform will be discussed and illustrated by a use case.

\section{Background}

Platforms are building the new digital infrastructure of our economy by offering new types of collaboration within value creating networks. It means that platforms map business systems in which actors and their products as well as processes become independent from the used hardware. Regarding product-service-systems platforms provide the specific cooperation between product manufacturer and service providers. Services platforms are a perfect opportunity to combine physical and digital services as a so called smart service. Meanwhile platforms define standards, tools, processes and interfaces. Therewith they characterize the game rules of interaction between the actors and objects [6;7]. To get to the bottom of platforms hereinafter the basics of service engineering, service networks and virtual enterprises. Service Engineering 
deals with the question of how to develop new services including product-servicesystems.

Service Engineering describes the target orientated planning and design of services [8;9]. According to intelligences from product and software development the core element of service engineering is the process design of services [10]. Therefore service engineering follows an iterative approach, utilizes methods and tools to measure efficiency as well as effectiveness of services. The target is to provide high quality services [11;12]. Based on the work of JASCHINSKI [13] a DIN-standard (DIN is the German Institute for Standardization) had been developed in the form of a reference process. Due to the fact that services are more and more provided within a service networks [14] the question of cooperation and collaboration becomes a key challenge. Though the reference process by DIN enables service development for networks the research landscape on cooperation and networks cannot be seen as homogeneous in general. There are rather various theories which in each case are based on insights from different business sectors $[15 ; 16]$. Nevertheless the research field of networks can be divided by three main characteristics. The relation between network partners can be seen as the main characteristic. Further the examined phase within the evolution process of a network helps to structure research on networks. As the third characteristic the perspective on the network is quoted [10].

A closer look should be taken into virtual enterprise structures because these are also aiming at collaboration between different organizations. Matos lines out that those virtual enterprises are information centered and its concepts had been developed to maximize reactivity between the actors. For instance in engineering this goes hand in hand with concurrent and co-engineering. Virtual enterprises request a management system to organize its activities and procedures. On the working level technical constraints like interoperability can be seen quite often but in general there is a strong need to define interfaces on all levels [17]. To prevent a large, complex and uncontrollable system MATOS proposes need-oriented acting. Therefor he divides virtual enterprises structures into three different classes by its complexity and lifetime. The first type of structures is based on a single market opportunity with a short term perspective. These need only a few co-working activities and work mostly in asynchronous collaborative phases. The system controls on a high level while subactivities have to be managed by the internal departments. Each sub-activity than has to be assigned to a specific virtual enterprise member who confirms on in- and output. The states of synchronization, resources and the actors themselves have to be determined by the global control system. In the result the system has to provide information by an Inter-Organizational Information System (IOIS) and a partner management system. The second type of virtual enterprises is characterized by more complex collaborations crossing company boundaries meaning collaborations between companies, its partners, customers, suppliers and whole markets [17]. This implies a possible global exchange, partnership or even subcontracting. In the resulting increase of coordination expenditure these types of extended enterprises have to connect external supply chains and information systems with internal systems. In addition the requirement of a high flexibility comes up. For partnerships where robustness and reactivity are the main focus, virtual enterprise structures as a 
consortium are recommended. Here internal competition could lead to more efficient resource consumption but results simultaneously to less flexibility.

Platforms are tackling a hand full of challenges within service design, value-adding networks and especially in digitalized virtual enterprises. They allow new business models and extend value streams. It is foreseen that platforms become dominant in value-adding networks by defining standards of collaboration. Existing manufacturer and service providers have to be aware of the upcoming risk of their replaceability in value streams or networks. Especially small and medium enterprises should use the opportunity to use open platform structures. These also prevent monopoly-like structures with in a single digital market. Summarizing platforms save employment and make growth potential accessible by providing optimal and modular types of collaboration.

\section{Framework Conditions Forming Collaborative Networks on Smart Service Platforms}

Innovative service-engineering provided by two or more companies forming collaborative networks on service platforms is hindered by some challenges. These challenges can be addressed and overcome by framework conditions which the platform must meet. In this chapter these framework conditions will be introduced and explained. In the following chapter these frameworks are illustrated by a usecase, covering the service engineering of maintenance services.

As stated above, some approaches (BAUER and SCHOBERT as well as ZAHN and STANIK $[18 ; 19])$ described service engineering in collaborative networks. However, the smart service platforms face other challenges and therefore need other framework conditions.

Service engineering by collaborative networks on service platforms unleashes its potential by integrating cyber physical systems. Therefore each company connects its cyber physical system with the platform. By doing so these cyber physical systems are enabled to autonomously provide data on the platform, for the use of service engineering processes and simultaneously ask for service solutions on the platform. Therefore the platform has to provide different interfaces in order to enable every company to connect their cyber physical system to the platform. As these sensitive connections and data are exposed to the platform, a data security concept has to be developed in order to protect companies' data and IT-systems. This can be achieved by software programming, independent servers and server location as well as specific entry requirements for the platform which have to be passed by every participant. Additionally the availability of data has to be guaranteed. The engineering process on the platform can only be executed if the needed data is provided by the companies and their cyber physical systems [7].

Usually the data generated by cyber physical systems is unstructured information [7]. As the service engineering process on the platform can only handle structured and refined data.

Another framework condition is the critical mass of platform participants. A critical mass is achieved when the platform participants provide all the competencies, 
which allow them to form a collaborative network on the platform and engineer an innovative service for the demand of the costumer. This critical mass allows the access to all relevant data for the service engineering process.

Another framework condition is the operation of the platform itself. The platform can be operated by a third impendent party, by some participates of the platform or by all participants of the platform. However, a neutral operator establishes an atmosphere of trust for the participants of the platform [7].
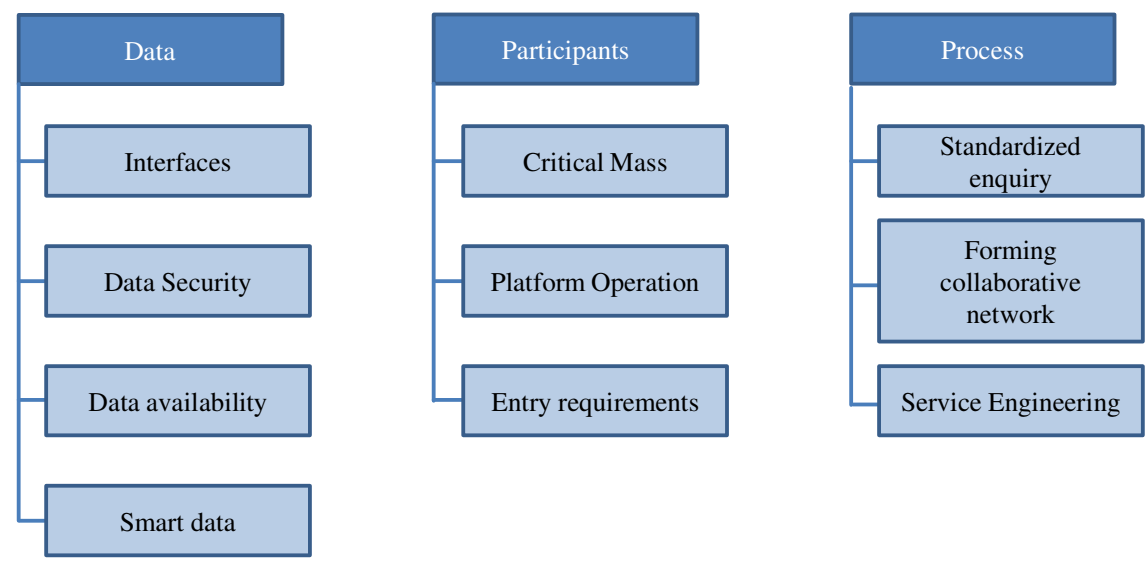

Fig. 1: Framework Conditions

Another framework condition are the entry requirements. Data security is a very important issue for smart service platforms, as they are connected to the cyber physical systems and infrastructure of each participant. The definition of entry requirements, which every participant has to pass, allows the operator to control the platform and help the participants to gain trust in to the platform.

The platform has also to provide framework conditions on the process level. First the platform needs a standardized process for enquiring demands of services. Basic characteristics need to be defined, which help the platform-management-system to match the service provider's competencies profile with the enquiry. Furthermore the platform has to provide framework conditions on how the collaborative network is formed on the platform. It has to define whether a party is included or excluded. Furthermore, framework conditions with regards to the service engineering process itself need to be defined. Requirements, competencies and restrictions need to be cleared by the platform in order to transfer relevant subtasks to the appropriate service provider.

An overview of the mentioned framework conditions is pictured in figure 1 . They are arranged under three generic terms which are data, participants and process. In the following chapter a use case is presented focusing on a complex maintenance task. The use case demonstrates the framework conditions in the course of an example. 


\section{Use Case - Complex Maintenance Task}

In the previous chapter, the framework conditions which provide the platforms required to facilitate a smart service engineering process were described and explained. This chapter exemplary demonstrates these framework conditions on the basis of a use case, focusing on a company, which has machines and software forming a cyber physical system. The company wants to be a participant of a smart service engineering platform, which has a critical mass of participants and an independent platform operator. Here the participants can form collaborative networks in order to engineer innovative services.

At first the company has to pass the entry requirements for the platform. This allows the platform operator to guarantee the data security and data availability of the platform. In the next step, a connection between the company's cyber physical system and the platform has to be established.

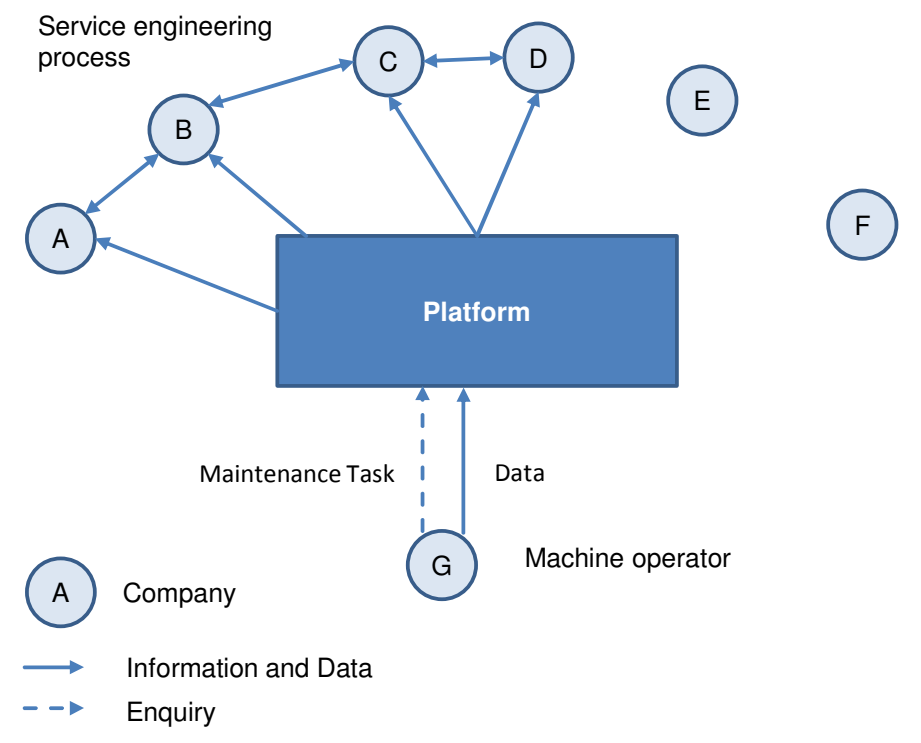

Fig. 2: Use-Case - Complex Maintenance Task

During operation the company's cyber physical system detects a demand for a complex maintenance task, which neither can be processed by the company itself nor by one subcontractor. Therefore the company's system autonomously enquires this complex maintenance task on the platform. This enquiry is standardized by a set of specific features, which inform the network about the characteristics of the maintenance task (e.g. duration, subtask and price). The company's system transfers only a set of refined data on to the platform. The platform then autonomously forms a collaborative network of specific service providers (participants of the platform) whose competencies match the characteristics of the maintenance task. They share the provided data on the platform in order to engineer the service for the costumer. 


\section{Conclusion}

Digitalization is changing the value adding structure in various industries. (cf. iTunes, amazon and Uber) However, some obstacles for digitalization can be identified, which define the pace of the digitalization especially in the industrial service sector. Value adding networks form digital ecosystems where producer, industrial service provider and software companies collaborate and engineer innovative services. The data need for the service engineering process is generated by the cyber physical systems of each company participating with the platform.

The paper introduced ten framework conditions. They arranged under three generic terms named data, participants and process. The framework conditions interfaces, data security, data availability and smart data are sorted under the term "data". The term "participants" include critical mass, platform operation and entry requirements. The last term is "process". This term aggregates standardized enquiry, process of forming collaborative network and service engineering process. Platforms meeting these conditions, allow a collaborative service engineering process with data generated form cyber physical systems. In chapter four these framework conditions are illustrated by a use case.

In a next step the framework conditions can be used in order to design and program a platform for collaborative service engineering processes.

\section{References}

1. Institut für Demoskopie Allensbach (Ed.): Die Zukunft der digitalen Gesellschaft. Ergebnisse einer repräsentativen Befragung (2014)

2. Kreutzer, R. T., Land, K.-H.: Digitaler Darwinismus. Der stille Angriff auf Ihr Geschäftsmodell und Ihre Marke. Das Think!Book. In: Digitaler Darwinismus (2013)

3. Redlich, T., Wulfsberg, J. P.: Wertschöpfung in der Bottom-up-Ökonomie. Springer-Verlag (VDI-Buch), Heidelberg, New York (2011)

4. Meier, H.: Integrierte Industrielle Sach- und Dienstleistungen. Vermarktung, Entwicklung und Erbringung hybrider Leistungsbündel. Springer, Berlin, Heidelberg (2012)

5. Brynjolfsson, E., McAfee, A.: The second machine age. Work, progress and prosperity in a time of brilliant technologies. 1. ed., Norton, New York (2014)

6. Westkämper, E.: Digitale Produktion. Springer Vieweg, Berlin (2013)

7. Kagermann, H., Riemensperger, F.: Smart Service Welt. Umsetzungsempfehlungen für das Zukunftsprojekt Internetbasierte Dienste für die Wirtschaft. acatech - Deutsche Akademie der Technikwissenschaften - Arbeitskreis Smart Service Welt, Berlin (2014)

8. Liestmann, V.: Dienstleistungsentwicklung durch Service Engineering. Von der Idee zum Produkt. Aachen, p. 23 (2001)

9. Bullinger, H.; Scheer, A.: Service Engineering - Entwicklung und Gestaltung innovativer Dienstleistungen. In: Bullinger, H.; Scheer, A. (eds.): Service Engineering: Entwicklung und Gestaltung innovativer Dienstleistungen. 2. ed., Springer, Berlin, p. 3-17 (2006)

10. Thomassen, P.: Kooperationskonzepte für Servicenetzwerke am Beispiel der erneuerbaren Energien. Apprimus Verlag, Aachen (2013)

11. Gudergan, G.: Service Engineering: Multiperspective and lnterdisciplinary Framework for New Solution Design. In: Maglio, P. P.; Kieliszewski, C. A.; Spohrer, J. C. (eds.) 
Handbook of Service Science. Springer Science + Business Media, LLC, Boston, p. 387 $418(2010)$

12. Schuh, G.; Friedli, T.; Gebauer, H.: Fit for Service: Industrie als Dienstleister. Hanser, München (2004)

13. Jaschinski, C.: Qualitätsorientiertes Redesign von Dienstleistungen. Shaker, Aachen (1998)

14. DIN - Deutsches Institut für Normung e.V.: Standardisierter Prozess zur Entwicklung industrieller Dienstleistungen in Netzwerken. DIN PAS 1082. Beuth, Berlin (2008)

15. Nawatzki, J.: Integriertes Informationsmanagement. Die Koordination von Informationsverarbeitung, Organisation und Personalwirtschaft bei der Planung, Durchführung, Kontrolle und Steuerung des Einsatzes neuer Informationstechnologie in der Unternehmung. Eul, Bergisch Gladbach (1994)

16. Cooper, R. G., Edgeti, S. J.: Product development for the service sector. Lessons from market leaders. Perseus, Cambridge, Mass (1999)

17. Camarinha-Matos, L. M., Afsarmanesh, H.: Matos Collaborative networks: a new scientific discipline. Journal of Intelligent Manufacturing, 16, pp. 439 - 452 (2005)

18. Bauer, C.; Schobert, A.: Auftragsinduzierte Konfiguration von Produktionsnetzwerken in der Dienstleistungswirtschaft. Arbeitsbericht Wirtschaftsinformatik II Nr. 01/2002, Universität Nürnberg, Nürnberg (2002)

19. Zahn, E.; Stanik, M.: Integrierte Entwicklung von Dienstleistungen und NetzwerkenDienstleistungskooperationen als strategischer Erfolgsfaktor. In: Bullinger, H., Scheer, A. (eds.): Service Engineering. Entwicklung und Gestaltung innovativer Dienstleistungen. Spinger, Berlin, p. 309 - 328 (2006) 